\title{
El sistema genético de Paspalum lillo (PoACeAe), esPeCIE ENDÉmica de las CataRatas del Iguazú
}

\author{
The genetic system of Paspalum lillo (Poaceae), An endemic species \\ FROM CATARATAS DEL IgUAZÚ
}

\author{
Anna Verena Reutemann ${ }^{1,3}{ }^{(D)}$, Eric J. Martinez ${ }^{1}$ (D), Gabriel H. Rua ${ }^{(D)}$, \\ Mara Schedler ${ }^{1}$, Julio R. Daviña ${ }^{3}$ y y Ana I. Honfi ${ }^{* *}$ (D)
}

\begin{abstract}
1. Instituto de Botánica del Nordeste, CONICET-UNNE, Facultad de Ciencias Agrarias, Universidad Nacional del Nordeste. Sargento Cabral 2131, 3400, Corrientes, Argentina.

2. Universidad de Buenos Aires, Facultad de Agronomía, Cátedra de Botánica Sistemática, Avenida San Martín 4453, C1417DSE Buenos Aires, Argentina.

3. Programa de Estudios Florísticos y Genética Vegetal, Instituto de Biología Subtropical CONICETUNaM, nodo Posadas, Universidad Nacional de Misiones, Rivadavia 2370, 3300 Posadas, Argentina.

*ahonfi@gmail.com
\end{abstract}

\section{Citar este artículo}

REUTEMANN, A. V., E. J. MARTINEZ, G. H. RUA, M. SCHEDLER, J. R. DAVIÑA Y A. I. HONFI. 2021. EI sistema genético de Paspalum lilloi (Poaceae), especie endémica de las Cataratas del Iguazú. Bol. Soc. Argent. Bot. 56: 253-268.

DOI: https://doi. org/10.31055/1851.2372.v56. n3.33273

Recibido: 4 Jun 2021

Aceptado: 23 Ago 2021

Publicado en línea: 8 Set 2021

Publicado impreso: 30 Set 2021

Editor: Gabriel Bernardello (DD

ISSN versión impresa 0373-580X

ISSN versión on-line 1851-2372

\section{SUMMARY}

Background and aims: Paspalum lilloi (Poaceae) is a diploid species, endemic of Iguazú Waterfalls and nearby areas. The reproductive biology and current geographical distribution of this species are poorly known. The aims of this work were to determine the genetic system and to delimit the endemism area and conservation status of the species.

M\&M: The genetic system was determined by cytoembryological analysis of ovules, viability and in vivo germination of pollen grains, pollen-pistils compatibility, fertility and flow cytometry of single seeds. Herbarium specimens and our collection sites delimited the geographical distribution.

Results: Meiotic embryo sacs of Polygonum type were observed in all analyzed ovules. No evidence of apomixis was detected. The mean pollen viability and in vivo pollen germination was $95.2 \%$ and $41.8 \%$, respectively. The pollen tube growth in the selfed stigmas was $59.2 \pm 6.39 \mu \mathrm{m} / 3 \mathrm{~h}$. Seed set in self-pollination was $93.6 \%$ and decreased to $52.7 \%$ when there was heterospecific pollen available. Seeds analyzed by flow cytometric seed screen showed an embryo: endosperm ratio 2:3 indicated a sexual origin. Paspalum lilloi is a reophile and rupicolous species, specialized in fast-moving waters of waterfalls and it is a critically endangered endemism of Iguazu Waterfalls, in South America.

Conclusions: $P$. lilloi is sexual, self-compatible and self-fertile species. Has a highly specialized habitat, which conservation will be a key step to avoid its extinction.

\section{KEY WORDS}

Autogamy, endemism, fertility, heterospecific pollination, Paspalum lilloi, pollen-pistil compatibility.

\section{RESUMEN}

Introducción y objetivos: Paspalum lilloi (Poaceae) es una especie diploide y endémica de las Cataratas del Iguazú y áreas circundantes, cuya biología reproductiva y área de distribución geográfica actual es desconocida. Los objetivos de este trabajo son conocer su sistema genético y delimitar la distribución y estado de conservación del endemismo.

M\&M: El sistema genético se determinó mediante citoembriología de sacos embrionarios, viabilidad y germinación in vivo de granos de polen, compatibilidad polen-pistilo, fertilidad y análisis de semillas por citometría de flujo. El área de distribución geográfica se delimitó mediante especímenes de herbario y colecciones propias.

Resultados: Se observaron sacos embrionarios meióticos de tipo Polygonum en todos los óvulos analizados. La viabilidad media y germinación in vivo del polen fue de $95,22 \%$ y $41,79 \%$, respectivamente. La tasa de crecimiento medio del tubo polínico en el estigma propio fue de $59,2 \pm 6,39 \mu \mathrm{m} / 3 \mathrm{~h}$. La producción de semillas en autopolinización fue del $93,61 \%$ y disminuyó al $52,72 \%$ cuando hay oferta de polen heteroespecífico. Los cariopsis analizados por citometría de flujo mostraron una relación de ploidía embrión: endospermo 2: 3, indicando un origen sexual. Paspalum lilloi es una especie reófila, rupícola y adaptada a saltos y cascadas, cuyo endemismo está en peligro crítico y circunscripto a las Cataratas del Iguazú.

Conclusiones: $P$. lilloi es una especie sexual, autocompatible y autofértil, adaptada a hábitats altamente especializados, cuya conservación resultará clave para evitar su extinción.

\section{Palabras clave}

Autogamia, compatibilidad polen-pistilo, endemismo, fertilidad, Paspalum lilloi, polinización heteroespecífica. 


\section{INTRODUCCIÓN}

Las especies de Paspalum L. se distribuyen desde Norteamérica hasta los $40^{\circ}$ de latitud $\mathrm{S}$ en Argentina y Chile (Chase, 1929; Nicora \& Rúgolo de Agrasar, 1987; Zuloaga \& Morrone, 2005; Zuloaga et al., 2014). El centro de diversidad se halla en la región tropical de América, siendo particularmente abundante en Brasil (Chase, 1929; Valls, 1987). En Argentina, la Mesopotamia es la región con mayor diversidad de especies (Morrone \& Zuloaga, 2012).

Paspalum se caracteriza por la presencia mayoritaria de especies con número básico de cromosomas $x=10$ y la existencia de distintos niveles de ploidía, que van desde diploides $(2 x)$ hasta hexadecaploides $(16 x)$ (Honfi et al., 1990; Hojsgaard et al., 2009; Honfi et al., 2021). Se estima que el $80 \%$ de las especies estudiadas son poliploides y que la mitad de éstas son tetraploides (Quarin, 1992; Ortiz et al., 2013). Todos los diploides tienen comportamiento cromosómico regular en la meiosis, con apareamiento cromosómico bivalente y segregación normal (Quarin, 1992; Ortiz et al., 2013; Honfi et al., 2021).

Los diploides del género son reproductiva y funcionalmente sexuales, y la mayoría de los poliploides exhiben apomixis de tipo apospórica (Ortiz et al., 2013). La apomixis es una forma de reproducción asexual donde los gametos son producidos sin meiosis y se desarrolla un embrión clonal, por lo tanto, genéticamente idénticos a la planta madre (Nogler, 1984; Hojsgaard \& Shartl, 2021). La mayoría de los diploides de Paspalum presentan un sistema de apareamiento por autoesterilidad $(75 \%) \mathrm{y}$, por lo tanto, se comportan como alógamos, mientras que el $25 \%$ restante son autofértiles y autógamos (Quarin, 1992; Ortiz et al., 2013). Los estudios de compatibilidad polen-pistilo en Paspalum son fragmentarios (Burson, 1986) y se han realizado en algunas especies diploides o poliploides tales como, P. bertonii Hack., P. dedeccae Quarin, P. denticulatum Trin., P. distichum L., P. inaequivalve Raddi, P. palustre Mez, P. ramboi Barreto (Quarin \& Burson, 1991), P. fasciculatum Willdenow ex Fluggé (Urbani, 1996), P. hydrophilum Henrard, P. palustre Mez (Martínez \& Quarin, 1999), P. chaseanum Parodi, P. plicatulum Michx., P. simplex Morong. (Espinoza \& Quarin, 1997), P. lenticulare Kunth, P. limbatum Henrard y P. guenoarum Arechav. (Espinoza et al., 2001), entre otras. Estos trabajos indican que la autofertilidad en Paspalum está generalmente relacionada con la poliploidía y la apomixis pseudogámica (ver también Quarin, 1999), y raramente con diploidía y sexualidad.

La diversidad taxonómica de Paspalum en América es compleja y las aproximadamente 312-330 especies descriptas se encuentran agrupadas en 4 subgéneros, Ceresia (Pers.) Rchb., Paspalum, Anachyris (Nees) Chase y Harpostachys (Trin.) S. Denham (Chase, 1929; Denham, 2005; Zuloaga \& Morrone, 2005; Morrone et al., 2012; Scataglini et al., 2014), que incluyen una gran variabilidad morfológica, citológica y reproductiva. La mayor parte de sus especies han sido reunidas en grupos informales en base a sus afinidades morfológicas y ecológicas, como el ciclo de vida y caracteres de las inflorescencias y espiguillas (Chase, 1929) que han sido mantenidos hasta el presente (Zuloaga \& Morrone, 2005) ante la falta de una filogenia suficientemente resuelta y estable que refleje grupos monofiléticos. El grupo informal Bertoniana reúne plantas perennes, cespitosas, con inflorescencias compuestas por 2 a 11 racimos, con espiguillas elipsoides y pilosas, con gluma superior y lemma inferior superando el largo del antecio superior, palea superior libre en el ápice, láminas con costillas marcadas en la cara adaxial y cariopsis con hilo linear (Parodi \& Nicora, 1966 inéd.; Türpe, 1967; Aliscioni, 2000; Zuloaga \& Morrone, 2005). El grupo comprende sólo dos especies filogenéticamente relacionadas, que crecen en ambientes húmedos, junto a cascadas de agua, Paspalum lilloi Hack. y $P$. bertonii Hack. (Zuloaga et al., 2003; Hojsgaard et al., 2009; Rua et al., 2010). La monofilia del grupo tiene alto soporte tanto por los datos morfológicos como moleculares (Aliscioni, 2002; Rua et al., 2010).

Paspalum lilloi es una especie que suele encontrarse en paredones o pendientes rocosas, sobre cascadas y saltos, o bordes de ríos del noreste de Argentina, sureste de Paraguay y suroeste del Brasil, principalmente en la zona de las Cataratas del Iguazú (Zuloaga \& Morrone, 2005; Hojsgaard et al., 2009). Actualmente, estos ambientes se van transformando por actividades antrópicas, como la construcción de represas hidroeléctricas sobre el Rio Paraná, y la perdida de hábitat debido a las fluctuaciones en el régimen hídrico afectan la supervivencia de estas especies higrófilas. Los antecedentes cromosómicos indican que se trata de una especie diploide con $2 n=2 x=20$ cromosomas, que se comportan regularmente en la meiosis y que posee un cariotipo unimodal con 20 cromosomas metacéntricos (Hojsgaard et al., 2009; Reutemann et 


\section{A. V. Reutemann et al. - Sistema genético de Paspalum lilloi}

al., 2017). La información disponible sobre el modo de reproducción, el síndrome de polinización, la producción de semillas, el mantenimiento en cultivo y su estado de conservación en la naturaleza es inexistente, y por tal razón los objetivos de este trabajo son conocer el sistema genético mediante análisis del modo reproductivo, compatibilidad polen-pistilo y fertilidad, y delimitar el área y estado de conservación del endemismo de P. lilloi.

\section{Material y Métodos}

\section{Material vegetal}

Los ejemplares de $P$. lilloi fueron coleccionados en las Cataratas del Iguazú, dentro del sector ubicado en el Parque Nacional Iguazú, provincia de Misiones, Argentina (Fig. 1A- B). Los ejemplares de herbario están depositados en el Herbario del Instituto de Botánica del Nordeste (CTES) y en el Herbario 'Gaspar Xuárez' (BAA) de la Facultad de Agronomía, Universidad de Buenos Aires. Las plantas vivas se mantuvieron en cultivo en el Jardín Botánico 'Lucien Hauman' de la FAUBA (Buenos Aires), y en los bancos de germoplasma de IBONE (Corrientes) e IBS (Posadas), Argentina.

Material estudiado: (con * se señalan los materiales mantenidos bajo cultivo).

Material: ARGENTINA. Prov. Misiones. Dto. Iguazú, Parque Nacional Iguazú, Cataratas del Iguazú, 12/1/1994, Rúa et al. 127 (BAA)*. Dto. Iguazú, Salto Iguazú (Bañadas), 7/10/1910, Stuckert 22453 (W, G, LIL); 7/10/1910, Lillo 10526 (W, G, LIL, US, F); 1/8/1964, Burkart 25588
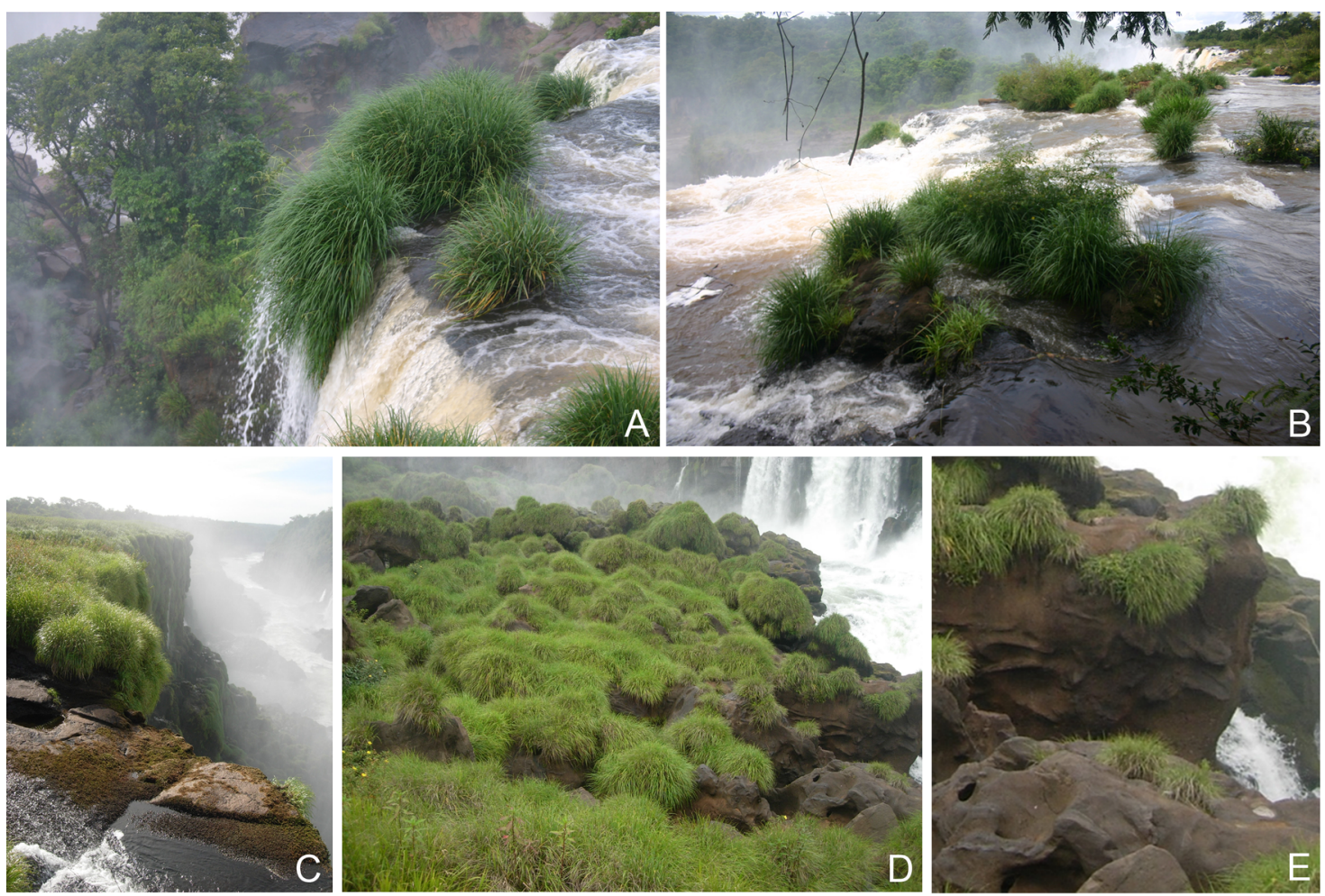

Fig. 1. Modo de vida natural de P. lilloi. A. Hábitat especializado del endemismo. Nótese el borde de la cascada de agua, torrentoso. B. Sitio de colección de Martínez et al. 3 en el circuito superior de las Cataratas del Iguazú, Misiones, Argentina. Nótese el aspecto general de las plantas y la distribución de individuos de la población. C. Pastizal higrófilo monoespecífico de P. lilloi. D-E. Condiciones ecológicas en Cataratas del Iguazú. Parque Nacional Iguazú, Misiones, Argentina. 
(SI); Rodríguez s.n, (BAA). Dto. Iguazú, Cataratas del Iguazú, Puerto Aguirre, 24/1/1922, Parodi 4376 (BAA, US). Dto. Iguazú, Parque Nacional Iguazú, Cataratas del Iguazú, 15/10/1993, Cabrera et al. 175 (SI). Cataratas del Iguazú, 18/1/1918, Hauman 11387 (SI); 28/8/1945, Krapovickas 2451 (SI). Cataratas del Iguazú, Salto Mbigua, 17/12/2013, Martínez et al. 3 (CTES)*. Cataratas del Iguazú, Garganta del Diablo, 28/3/2004, Hojsgaard 335 (MNES). Cataratas del Iguazú, Isla San Martín, frente al Salto San Martín, 12/12/1983, Hunziker 10939 (SI); 15/10/1993, Tressens 4567 (CTES); 4/12/1993, Vanni 3219 (CTES). Cataratas del Iguazú, Isla San Martín, 4/3/1995, Zuloaga 5230 (SI), 4/3/1995, Zuloaga 5339 (SI), 4/3/1995, Zuloaga 5239 (MO, NY). Cataratas del Iguazú, 20/12/1991, Vanni 3025 (CTES); 4/12/1993, Vanni 3224 (CTES); 4/12/1993, Vanni 3619 (CTES). Cataratas del Iguazú, Meseta De Los Tres Mosqueteros, 10/12/1995, Vanni 3912 (CTES). Cataratas del Iguazú, camino a Puerto Canoas, 3/3/1995, Zuloaga 5226 (SI, MO). Misiones, Posadas, 1/12/1900, Gallardo 11386 (SI). BRASIL. Estado Paraná, Salto Iguaçu, Rambo 53619 (US). Mun. Foz do Iguaçu, Parque Nacional do Iguaçu, 24/1/1967, Hatschbach 23168 (K, NY); 8/10/1946, Kuhlmann 57729 (IAN, US), 8/3/2018, Valls 23168 (NY). PARAGUAY. Dto. Alto Paraná. "Yguy". Chodat, R. s.n. (G).

\section{Cultivo ex situ}

A los fines de conocer cuáles serían las condiciones apropiadas para cultivar esta especie, se recrearon parcialmente las condiciones especiales de crecimiento reófilo de $P$. lilloi. Los macollos fueron trasplantados a una maceta grande con sustrato profesional enriquecido con nutrientes, y se colocaron en un circuito hídrico semipermanente que simula una cortina (vertical) de agua construida sobre la pared externa del invernáculo del IBONE en Corrientes (Argentina). La columna de agua cae dentro de una canaleta que simula una corriente horizontal en la zona donde se colocaron las macetas. Simultáneamente, otras macetas se mantuvieron en cultivo también en maceta grande, sin cortina de agua, pero con plato recipiente de agua permanente $\mathrm{y}$ riego periódico diario, en Posadas, Misiones. Ambos tratamientos a la intemperie y sujetos a las condiciones climáticas imperantes. Las plantas fueron obtenidas en diciembre de 2013 (Martínez et al. $3 \# 1, \# 2, \# 3)$ y florecieron solamente en 2014 en Posadas, Misiones. Por otro lado, en los años 2016, 2017 y 2019 florecieron las plantas cultivadas bajo cortina de agua semipermanente en Corrientes. Posteriormente, las plantas de Corrientes se trasladaron dentro del invernáculo en marzo del año 2020, y no volvieron a florecer aun con nuevos repiques, fertilización y riego diario. El ejemplar Rua 127 (BAA 22741) se mantiene en cultivo en maceta desde 1994 en Buenos Aires, donde nunca floreció. Las matas de P. lilloi en cultivo se caracterizan por crecimiento cespitoso y las hojas son discoloras, con el haz verde brillante y el envés estriado y glauco (Fig. 2A). Los ejemplares de P. lilloi Martínez et al. 3 y Rua 127 presentan diferencias principalmente en el ancho y largo de las hojas, siendo mayores en la accesión Martínez et al. 3 (Fig. 2B). Las plantas se adaptaron a las condiciones de cultivo en todos los casos, pero la floración en cultivo solo ocurrió en las plantas ubicadas en el circuito hídrico del IBONE bajo una corriente de agua continua y llovizna permanente.

\section{Análisis de óvulos maduros por citoembriología}

Los sacos embrionarios maduros al momento de la antesis fueron analizados mediante citoembriología clásica en la accesión Martínez et al. 3. Para ello, se fijaron inflorescencias al momento de la antesis en FAA (etanol 70\%: formaldehído: ácido acético 18:1:1) al menos durante $24 \mathrm{~h}$. Luego, fueron conservadas en etanol $70 \%$ a $4{ }^{\circ} \mathrm{C}$ hasta su análisis. Se diseccionaron 30 pistilos y se conservaron en etanol $70 \%$ en heladera. Los pistilos fueron deshidratados en una serie de combinaciones de alcohol etanol y alcohol terbutílico en concentración creciente, e incluidos en parafina para obtener cortes longitudinales de 12 $\mu \mathrm{m}$ de espesor en micrótomo rotatorio. Los cortes obtenidos fueron coloreados con técnica clásica de safranina y fast green, y se montaron en bálsamo de Canadá.

Por otra parte, esta metodología se combinó con el análisis mediante la técnica de diafanizado de pistilos con metilsalicilato propuesta por Young et al. (1979) con las modificaciones introducidas por Zilli et al. (2015). Los pistilos diseccionados $y$ conservados en etanol $70 \%$, se colocaron en peróxido de hidrogeno al $3 \%$ por $2 \mathrm{~h}$. Luego, fueron sometidos a deshidratación en una serie de etanol creciente $(50 \%, 70 \%, 95 \%, 100 \%)$ por $30 \mathrm{~min}$ cada 


\section{A. V. Reutemann et al. - Sistema genético de Paspalum lilloi}
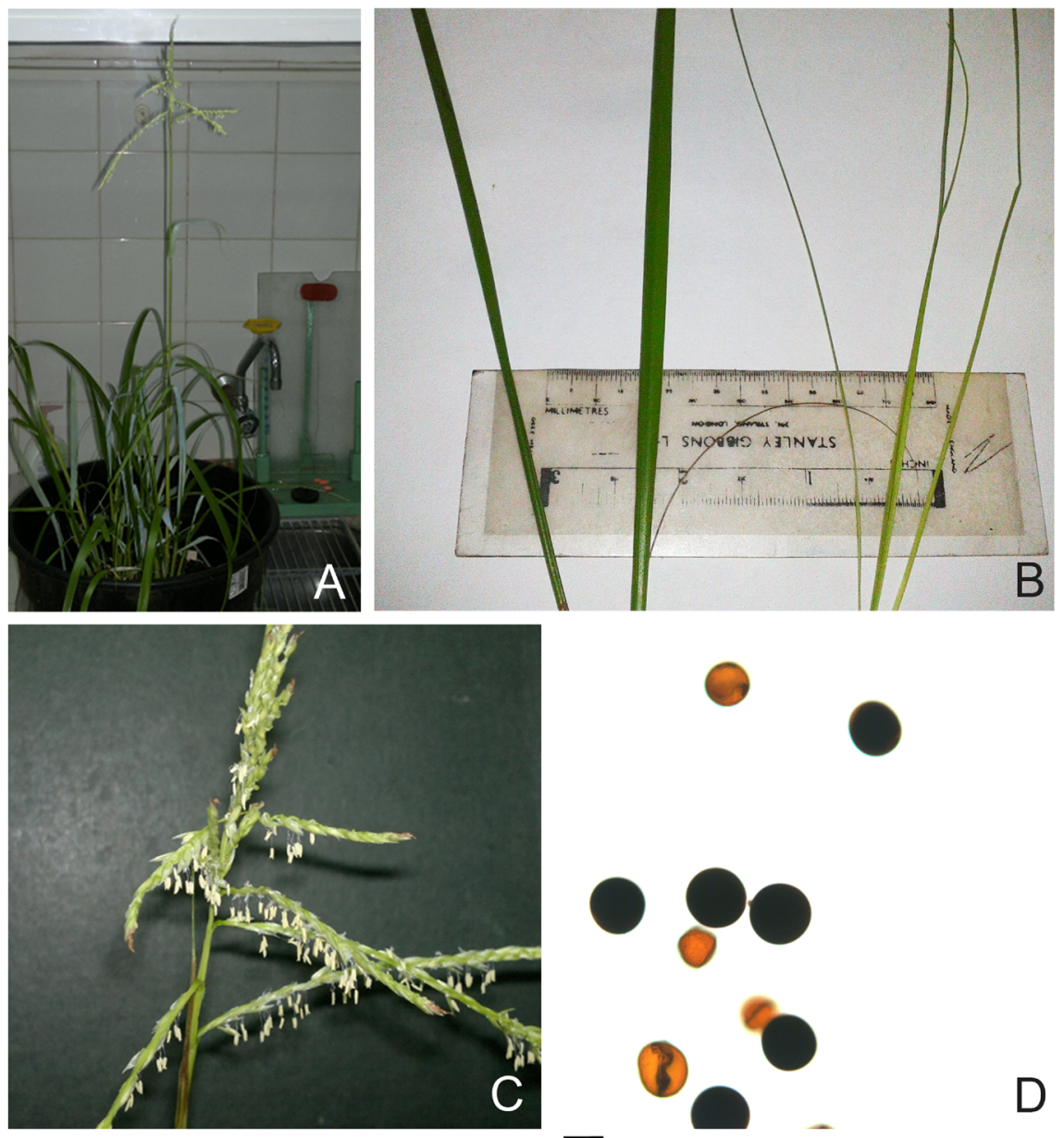

Fig. 2. Paspalum lilloi. A. Planta en antesis (Martínez et al. 3). Nótese las hojas discoloras. B. Detalle comparativo del ancho de las hojas entre accesiones: izq. Martínez et al. 3; der. Rua et al. 127, ambas provenientes de las Cataratas del Iguazú, Misiones, Argentina. C. Detalle de la inflorescencia con los racimos basales y medios en antesis y los superiores en pre-antesis. D. Polen coloreado con Lugol (viable) y no coloreado (inviable). Escala= D: $25 \mu \mathrm{m}$.

paso, y a clarificación en una serie de metilsalicilato: etanol $(50 \%, 75 \%, 85 \%)$ por 30 min cada paso, hasta la utilización de metilsalicilato puro para el diafanizado (por $12 \mathrm{~h}$ ). Los pistilos diafanizados fueron colocados en un portaobjetos con una gota de metilsalicilato y luego los óvulos fueron observados bajo un microscopio con dispositivo de contraste de interferencia diferencial (DIC).

Análisis de semillas por citometría de flujo

A partir del análisis individual de semillas mediante citometría de flujo(FCSS, Flow Cytometric
Seed Screen) se determinó simultáneamente el contenido relativo de ADN (2C) en tejidos del embrión y endospermo. Para ello, se empleó el citometro CyFlow ${ }^{\circledR}$ Space de Sysmex- Partec, que cuenta con una lámpara UV-LED (3 w a $365 \mathrm{~nm}$ ) y los filtros estándares para DAPI. Las mediciones del contenido relativo de ADN fueron realizadas de acuerdo con las instrucciones descritas en Galdeano et al. (2016). El análisis de los datos fue hecho con el software FloMax de Partec. Se consideró que las semillas de origen sexual tienen embriones constituidos por $[(n+n)=2 n=2 x=2 \mathrm{C}] \mathrm{y}$ endospermo 
$[(n+n)+n=2 n=3 x=3 \mathrm{C}]$, provenientes de la doblefecundación de la oósfera y los núcleos polares de la célula central respectivamente, por los núcleos cromosómicamente reducidos $(n)$ aportados por el polen. Si se trata de una planta diploide, en sus semillas de origen sexual el embrión también será diploide y el endospermo triploide. Se utilizaron hojas de frescas de Martínez et al. 3 como control externo, para asegurar que el valor $2 \mathrm{C}$ en los histogramas refiere a la condición diploide y semillas $(\mathrm{N}=17)$ de la misma accesión.

\section{Determinación de la viabilidad de polen}

La disponibilidad de polen viable al momento de la antesis se analizó con el método de coloración con Lugol (Iodo-Ioduro de potasio 1\%), a partir de polen fresco. Se determinó el porcentaje de granos de polen teñidos sobre un mínimo de 1000 granos analizados en 3 repeticiones de polen fresco y una de polen fijado en mezcla de Clarke (1851), etanol absoluto: ácido acético glacial $(\mathrm{v} / \mathrm{v} ; 3: 1)$ durante 12 - $24 \mathrm{~h}$, y luego coloreado con solución de Müntzing (glicerol y solución de carmín acético al $1 \%, \mathrm{v} / \mathrm{v}, 1: 1)$ por $24 \mathrm{~h}$.

\section{Medición del tamaño de granos de polen}

A partir de la muestra de polen fresco teñido con Lugol $1 \%$, se tomaron mediciones del diámetro sobre el eje polar de 60 granos de polen, considerando que en vista polar son circulares y en vista ecuatorial levemente elípticos. El valor del diámetro promedio se usó como referencia para la evaluación de la germinación in vivo del polen al momento de la antesis, y se consideró como germinado al grano de polen cuyo tubo polínico presentó una longitud igual o mayor a dicho diámetro (Dawkins \& Owens, 1993). Para las mediciones se utilizó el software ImageJ (Maryland, USA).

\section{Análisis de la compatibilidad polen-pistilo y germinación in vivo del polen}

La determinación de la compatibilidad polenpistilo, se realizó con la técnica de diafanización y coloración con azul de anilina de acuerdo con Kho \& Bäer (1968) en la accesión Martínez et al. 3. Se determinó la germinación de los granos de polen y el crecimiento del tubo polínico utilizando espiguillas fijadas bajo condiciones de autopolinización de individuos en cultivo.
Las inflorescencias fueron ensobradas la noche previa a la antesis para evitar la llegada de polen foráneo y garantizar el suministro de polen propio a los estigmas. Una vez iniciada la antesis, las inflorescencias se fijaron en etanol absoluto: ácido acético glacial ( $3: 1)$ durante 24 h y se diseccionaron diez pistilos por planta, a partir de espiguillas en antesis. También se fijaron espiguillas en postantesis a 3-4 h de iniciada la misma, considerando que la antesis no se inicia simultáneamente en todas las espiguillas de una inflorescencia. Para ello, se condujeron las macetas con las plantas en antesis al laboratorio y se observó su desarrollo (Fig. 2A). Las inflorescencias fijadas fueron enjuagadas una vez con etanol $70 \%$ para eliminar el polen no adherido a la misma. Los pistilos se colocaron en hidróxido de sodio $(\mathrm{NaOH}) 5 \mathrm{~N}$ durante $72 \mathrm{~h}$ en vidrio reloj a temperatura ambiente, luego se lavaron con etanol absoluto y se dejaron durante $24 \mathrm{~h}$ en solución de azul de anilina $0,1 \%$. Luego, se observaron las estructuras en microscopio de epifluorescencia utilizando portaobjetos cóncavos con una gota de solución de azul de anilina $0,1 \%$. Se analizó un número mínimo de 30 granos de polen por pistilo. Se consideraron germinados aquellos granos de polen cuyo tubo polínico tenía una longitud igual o mayor al diámetro promedio calculado previamente para los granos de polen. Se tomaron microfotografías usando el software Leica LAS V4.0 y para las mediciones se utilizó el software ImageJ (Maryland, USA).

\section{Estimación de la producción de semillas}

La producción de semillas se estableció mediante el porcentaje de espiguillas que desarrollaron grano (cariopsis). Esta determinación se realizó en condiciones de autopolinización en la accesión Martínez et al. 3. Para ello, se ensobraron inflorescencias en bolsas de papel sulfito antes de que se inicie la antesis y de esta manera se evitó la fecundación con polen de otras plantas. Las espiguillas autopolinizadas $(\mathrm{N}=94)$ se cosecharon al cabo de 25 días y luego se procedió a la separación y conteo de las que formaron cariopsis y las vanas.

Ensayos de autofecundación con polen heteroespecífico

Simultáneamente a los ensayos de autopolinización, se realizaron cruzamientos 


\section{A. V. Reutemann et al. - Sistema genético de Paspalum lilloi}

utilizando polen de P. bertonii (accesión Honfi 2147, Salto Tabay, Misiones, Argentina, MNES) sobre estigmas de $P$. lilloi, para observar la incidencia de polen foráneo heteroespecífico en la tasa de producción de cariopsis en comparación a la producción bajo autopolinización controlada de P. lilloi. Para ello, se ensobraron las inflorescencias de ambas especies el día previo a la antesis y se mantuvieron de ese modo durante 25 días hasta la cosecha. Las espiguillas de cada especie fueron discriminadas bajo una lupa y se separaron las fructificadas de las vanas. Se efectuaron 4 repeticiones del ensayo con las mismas plantas maternas y paternas en condiciones de invernáculo. La elección de $P$. bertonii se basó en la estrecha relación filogenética entre ambas especies y en la distribución simpátrica de las mismas.

Delimitación del área actual de ocurrencia del endemismo y estado de conservación

En base a la revisión exhaustiva de especímenes de herbarios, bases de datos disponibles y viajes de colección botánica realizados en el área durante varios años, se confeccionó una lista de especímenes de herbario, cuyas procedencias delimitan el área de ocurrencia actual del endemismo. En base a estos puntos de ocurrencia, y eliminando los registros duplicados, se elaboró un mapa de distribución geográfica actualizado para la especie utilizando el software DivaGIS (Hijmans et al., 2004). Se calculó el área del polígono convexo que encierra a los puntos, utilizando el paquete dismo del software R ( R Core Team, 2020; Hijmans \& Elith, 2017).

El estado de conservación de la especie fue determinado de acuerdo a los criterios establecidos por UICN v.14 (2019). Los criterios considerados por UICN son: A, Reducción del tamaño poblacional; B, Tamaño del área de distribución geográfica; C, Tamaño poblacional pequeño; $\mathrm{D}$, Población muy pequeña o distribución muy restringida; E, Análisis cuantitativo del riesgo de extinción. Las categorías definidas por UICN son nueve, sin embargo, se consideraron en la evaluación las categorías amenazadas En Peligro Crítico (CR), En Peligro (EN) y Vulnerable (VU). Para la asignación de la categoría correspondiente, se consideró todo el rango de distribución geográfica de $P$. lilloi.

\section{Resultados}

\section{Modo de reproducción}

A partir del análisis citoembriológico de espiguillas en antesis, se observó en cada óvulo la presencia de un único saco embrionario de origen meiótico (SEM), de forma elongada, ubicado sobre el eje micrópilo-chalazal. El $95,45 \%$ de los óvulos presentaron un SEM completamente desarrollado. El 5,55\% de los óvulos restantes presentaron sacos embrionarios abortados. En Paspalum lilloi, el SEM está constituido por un aparato oosférico formado por la oosfera y dos sinérgidas, una célula central con dos núcleos polares cuyos nucléolos son de tamaño prominente, y 3-7 antípodas. No se observó una mayor proliferación de antípodas en el polo chalazal del saco embrionario. Esta constitución del saco embrionario indica que es de tipo Polygonum (Fig. 3A-B).

Se analizaron un total de 17 semillas por citometría de flujo, y todas presentaron una proporción relativa de ADN del embrión: endospermo de 2:3, indicando que se originaron por una vía sexual (Fig. 4).

\section{Viabilidad y tamaño del polen}

La antesis en $P$. lillo $i$ es matutina y ocurre a partir de la media mañana (9:00h am). La antesis ocurre asincrónicamente en las espiguillas de una inflorescencia, iniciando en los racimos inferiores y prosiguiendo hacia los superiores (Fig. 2C). La viabilidad del polen promedio fue de $94,3 \%$ y se estimó a partir de 3620 granos de polen provenientes de 4 inflorescencias (Fig. 2D, Tabla 1). La viabilidad de polen fresco mostro un rango de variación entre $80,3-98,8 \%$ y la viabilidad de polen fijado fue de $92,0 \%$ (Tabla 1).

El diámetro promedio de los granos de polen coloreados fue de $36,24 \mu \mathrm{m} \pm 0,52$ y se estimó sobre un total de 60 granos medidos. Los granos de polen no coloreados fueron más pequeños que los coloreados y sobre un total de 30 granos, el tamaño medio fue de $28,0 \mu \mathrm{m} \pm 0,42$.

\section{Sistema de apareamiento y polinización}

A partir de la llegada del polen al estigma de $P$. lilloi, la polinización comienza con la adhesión de los granos de polen a la papila 


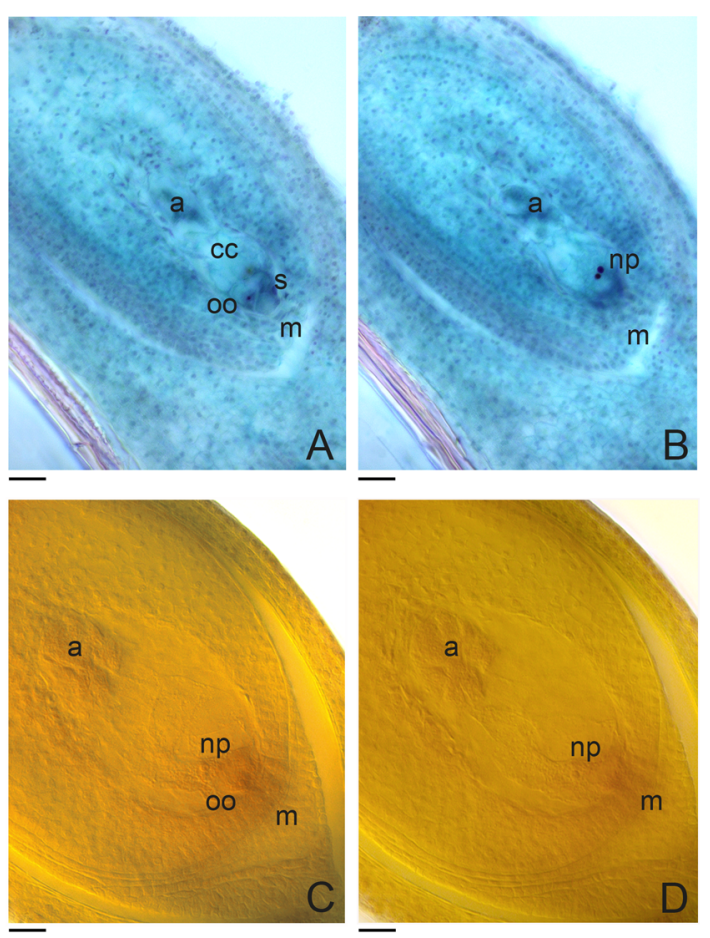

Fig. 3. A-B. Cortes consecutivos de un saco embrionario meiótico (SEM) maduro de Paspalum lilloi. A. Primer corte. Se observa el SEM ubicado sobre el eje micrópilo-chalazal. En el polo micropilar, se observa la oosfera (oo) con núcleo y nucléolo coloreados, y citoplasma de las sinérgidas (s). En la porción media, la célula central (cc) con muchas vacuolas y en el extremo chalazal las antípodas (a), con nucléolos de coloración rojo tenue. B. Segundo corte. En la célula central se observan 2 núcleos polares (np) con nucléolos prominentes y hacia la chalaza, más antípodas. C-D. Óvulo clarificado con un SEM. C. Primera imagen, aparato oosférico, célula central con grandes vacuolas y nucléolo de un núcleo polar, más varias antípodas. D. Segunda imagen, se observa segundo núcleo polar y antípodas. Abreviaturas = a: antípodas; $c c$ : célula central; $n p$ : núcleos polares; oo: oosfera; s: sinérgida. Escalas= A-D: 26,1 $\mu \mathrm{m}$.

estigmática (Fig. 5A-C, Fig. 6A) y prosigue con la hidratación y germinación del grano de polen (Fig. 5D-F) hasta alcanzar el micrópilo (Fig. 5AD).

La germinación de los granos de polen in vivo fue del $41,79 \%$ a $3-4 \mathrm{~h}$ posteriores a la antesis. Tomando en cuenta los valores de viabilidad del polen fresco y fijado (Tabla 1), se observó que la proporción de granos germinados en el pistilo fue menor a la esperada (Tabla 2). Los tubos originados de granos ubicados en la porción superior del estigma crecieron una corta distancia a lo largo de las ramas y pocos llegaron al eje central colector del estigma al cabo de 3-4 h. Los tubos polínicos en las porciones medias e inferiores del estigma también presentaron una elongación corta y sólo algunos alcanzaron el eje central. La tasa de crecimiento medio del tubo polínico in vivo fue de 59,2 $\pm 6,39 \mu \mathrm{m} /$ 3h. La máxima extensión de crecimiento del tubo polínico fue de $118,75 \mu \mathrm{m} / 3 \mathrm{~h}$, mientras que la mínima fue de $31,25 \mu \mathrm{m} / 3 \mathrm{~h}$, para el lapso post-antesis. Solo 1-3 tubos polínicos alcanzan el micrópilo del óvulo a las 3-4 h de iniciada la antesis. Los resultados indican que la fecundación se realiza a posteriori de al menos 4 $\mathrm{h}$ transcurridas del inicio del crecimiento del tubo polínico.

\section{Producción de semillas}

En condiciones de autopolinización, se obtuvieron 88 espiguillas con cariopsis completamente desarrollados, sobre un total de 94 espiguillas analizadas de una sola planta, por lo que la producción de semillas fue del 93,6\% (accesión Martínez et al. 3).

Los cuatro ensayos de polinización heteroespecífica produjeron una menor cantidad de semillas que las producidas por autopolinización. El promedio de producción de semillas fue de $52,7 \%$ (Tabla 2). Los cariopsis obtenidos son considerados producto de la autopolinización de $P$. lilloi, aunque no podemos descartar el origen hibrido de algunos de ellos.

\section{Área del endemismo y estado de conservación}

En base al material de herbario estudiado y viajes de exploración botánica al área potencial de ocurrencia de $P$. lilloi, se obtuvieron seis puntos de presencia, de los cuales cinco provienen de los saltos, cascadas y rápidos de las Cataratas del Iguazú (Argentina - Brasil) (Fig. 7). El especímen restante (Chodat s.n.; G) no fue incluido en el cálculo del área ocupada por la especie por tratarse de una geolocalización dudosa. Con los puntos de ocurrencia en Cataratas del Iguazú, se calculó un área poligonal convexa de $45,4 \mathrm{~km}^{2}$ 


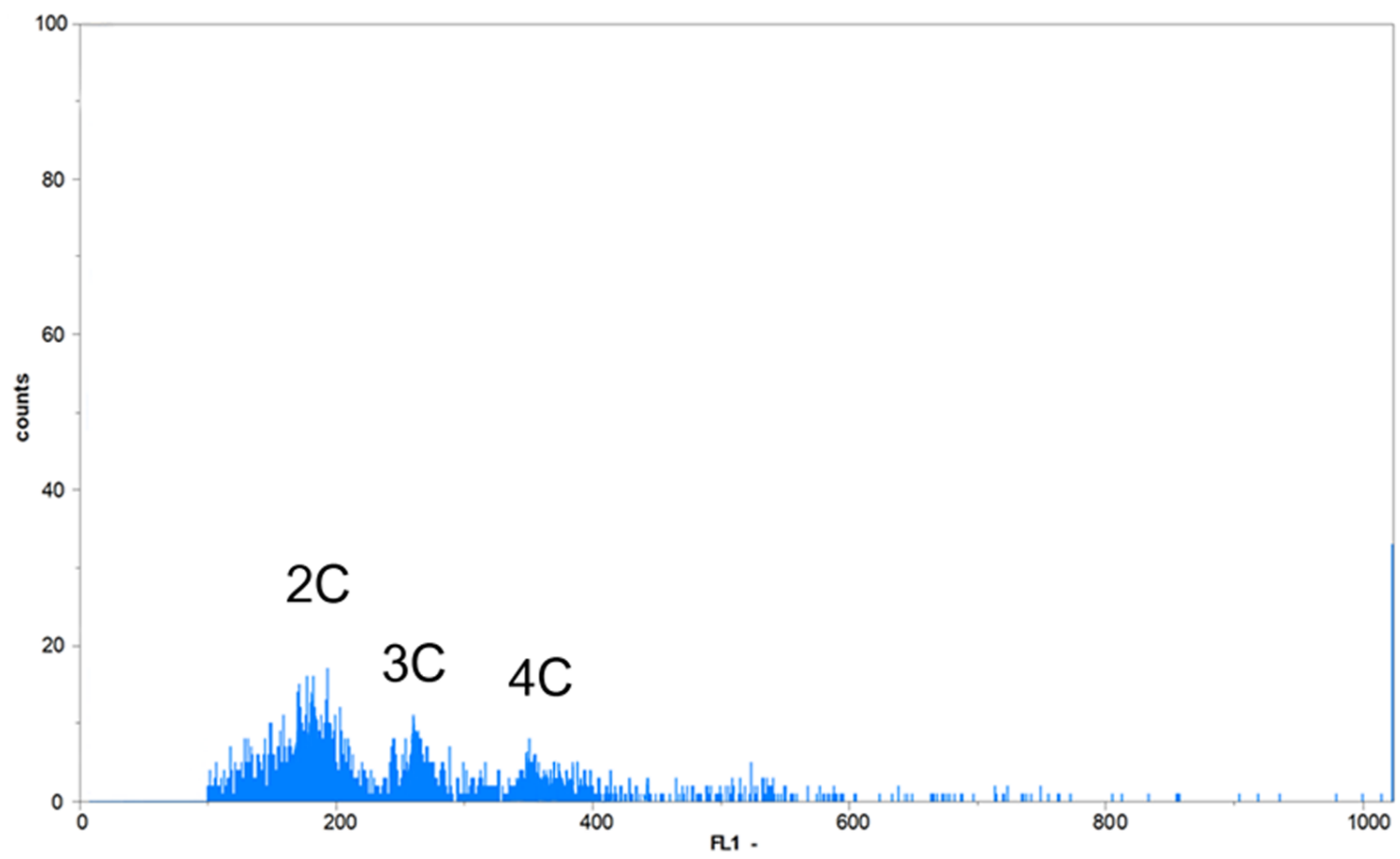

Fig. 4. Histograma representativo del análisis por citometría de flujo de semillas de $P$. lilloi. El histograma corresponde a una semilla de origen sexual, donde se observan los picos del embrión (2C) y endosperma (3C), ambos correspondientes a la fase G0/G1 del ciclo celular, y el pico correspondiente a la fase G2 del ciclo celular del embrión (4C).

(= 4543 ha). La ausencia de un mayor número de puntos de localización imposibilita realizar proyecciones fidedignas del área potencial o de futura ocurrencia.

Tomando como referencia los criterios descritos por la UICN v.14 para determinar si un taxón se encuentra dentro de las categorías

Tabla 1. Viabilidad del polen de P. lilloi.

\begin{tabular}{|lccc|}
\hline Material & $\begin{array}{c}\mathbf{N}^{\circ} \text { Granos } \\
\text { de polen } \\
\text { llenos }\end{array}$ & $\begin{array}{c}\mathbf{N}^{\circ} \text { Total } \\
\text { de granos } \\
\text { de polen }\end{array}$ & \% Viables \\
\hline Polen fresco & 1062 & 1095 & 97,0 \\
Polen fresco & 1112 & 1125 & 98,8 \\
Polen fresco & 321 & 400 & 80,3 \\
Polen fijado & 920 & 1000 & 92,0 \\
Total & 3415 & 3620 & 94,3 \\
\hline
\end{tabular}

amenazadas, $P$. lilloi pertenece a la categoría En Peligro Crítico, según los criterios B1ab (i, ii) + 2ab(i, ii). Esta clasificación significa que la especie posee una extensión de presencia inferior a $100 \mathrm{~km}^{2}$ (B1), que actualmente se conoce una única localidad geográfica y ecológica (a), ya que se encuentra restringida al área binacional de Cataratas del Iguazú (Argentina - Brasil) y que existe una disminución (b) en la extensión de presencia (i) y por ende del área de ocupación (ii) de la especie en al menos los últimos 10 años. El área de extensión de presencia (EOO) es el área contenida dentro de los límites calculados en el polígono convexo incluyendo todos los sitios conocidos donde se encuentra presente $P$. lilloi (Fig. 7). El área de ocupación (AOO) representa el área de hábitat adecuado actualmente ocupado por $P$. lilloi dentro del polígono convexo calculado, que en nuestra especie está estimado en $8 \mathrm{~km}^{2}$ (800 ha, B2), basándonos en los cálculos sugeridos por la IUCN v.14 para la estimación del AOO (Fig. 7). 
Bol. Soc. Argent. Bot. 56 (3) 2021
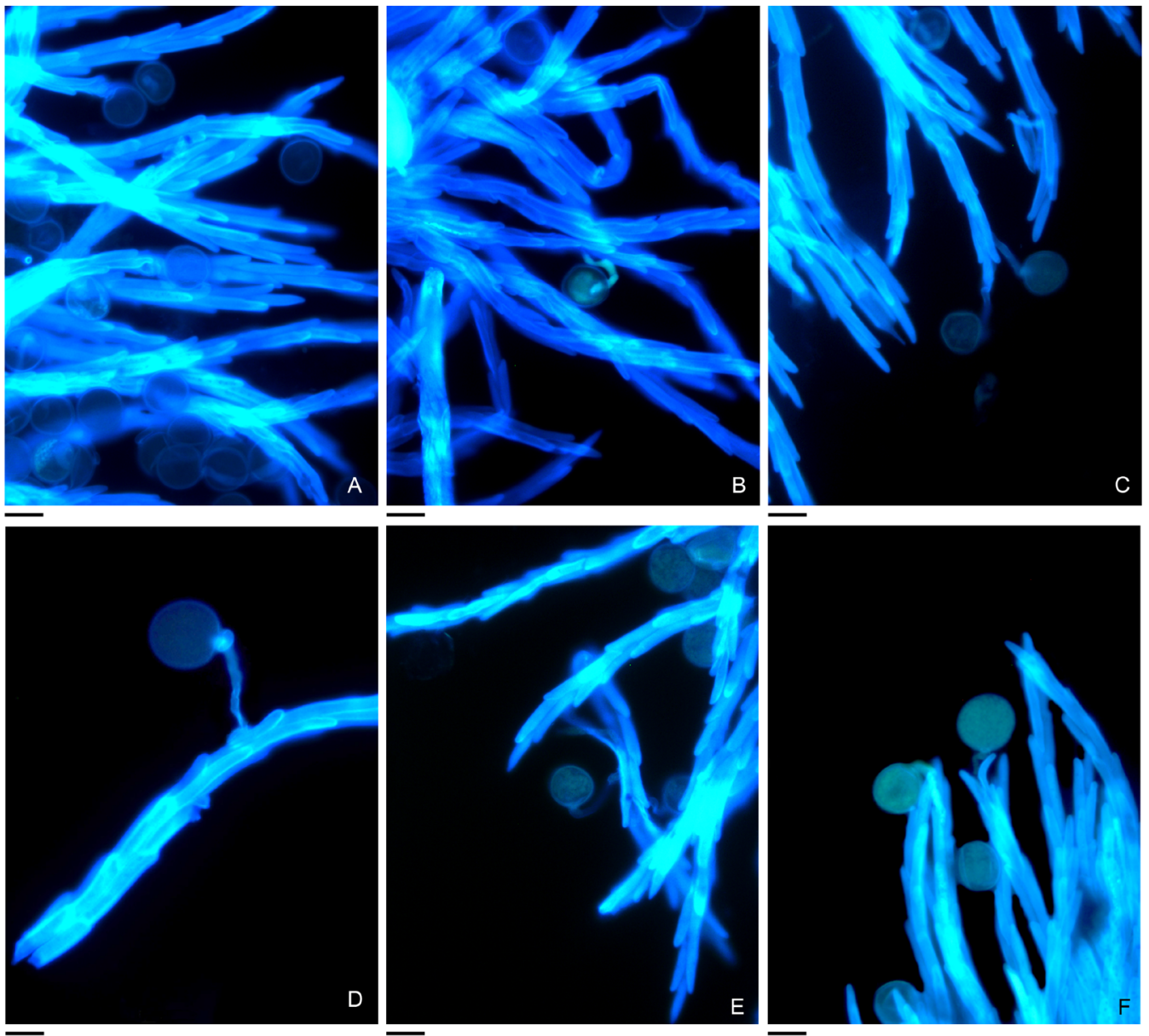

Fig. 5. Germinación in vivo del polen de P. lilloi. A: Granos de polen adheridos a las papilas estigmáticas. B y C. Grano de polen germinado. Nótese longitud del tubo polínico. D-F. Granos de polen germinados, con tubo polínico creciendo a través de las papilas estigmáticas. Escalas= A-F: $25 \mu \mathrm{m}$.

Tabla 2. Ensayos de polinización homoespecífica y heteroespecifica y producción de semillas de $P$. lilloi (Martinez et al. 3).

\begin{tabular}{|c|c|c|c|c|c|c|c|c|c|}
\hline \multicolumn{7}{|c|}{ Proceso de autopolinización } & \multicolumn{3}{|c|}{ Polinización heteroespecifica } \\
\hline $\begin{array}{l}\text { Total de } \\
\text { granos } \\
\text { de polen. }\end{array}$ & $\begin{array}{c}\text { Granos } \\
\text { de polen } \\
\text { adheridos } \\
\text { al estigma }\end{array}$ & $\begin{array}{c}\mathrm{N}^{\circ} \text { de } \\
\text { granos } \\
\text { germinados }\end{array}$ & $\%$ GP & $\begin{array}{l}\mathbf{N}^{\circ} \text { de } \\
\text { Tubos } \\
\text { polínicos } \\
\text { en el } \\
\text { Estigma * }\end{array}$ & $\begin{array}{c}\mathrm{N}^{\circ} \text { de } \\
\text { Tubos } \\
\text { polínicos } \\
\text { en el } \\
\text { Micrópilo ** }\end{array}$ & $\begin{array}{c}\mathrm{N}^{\circ} \text { de } \\
\text { espiguillas } \\
\text { de } P \text {. } \\
\text { Iilloi con } \\
\text { cariopsis } \\
\text { / Total }\end{array}$ & $\begin{array}{c}\text { Ensayo } \\
P . \text { lilloi } \uparrow \\
\text { (M3) X P. } \\
\text { bertonii }{ }^{1} \\
\text { (H2147) }\end{array}$ & $\begin{array}{c}N^{0} \text { de } \\
\text { espiguillas } \\
\text { de } P \text {. } \\
\text { Iilloi con } \\
\text { cariopsis } \\
\text { / Total }\end{array}$ & $\%$ \\
\hline \multirow{6}{*}{1390} & \multirow{6}{*}{809} & \multirow{6}{*}{581} & \multirow{6}{*}{41,79} & \multirow{6}{*}{581} & \multirow{6}{*}{ ca. $3(1-3)$} & \multirow{6}{*}{$88 / 94$} & 1 & $154 / 286$ & 53,84 \\
\hline & & & & & & & 2 & $56 / 80$ & 70,00 \\
\hline & & & & & & & 3 & $80 / 116$ & 68,97 \\
\hline & & & & & & & 4 & $87 / 233$ & 37,33 \\
\hline & & & & & & & Total & $377 / 715$ & 52,73 \\
\hline & & & & & & & $x \pm E . E$ & $59.47 \pm$ & \\
\hline
\end{tabular}

\footnotetext{
* 3 h post-antesis; GP: Germinación de granos de pollen; E.E.: error estándar
}

** $4 \mathrm{~h}$ post antesis 


\section{A. V. Reutemann et al. - Sistema genético de Paspalum lilloi}
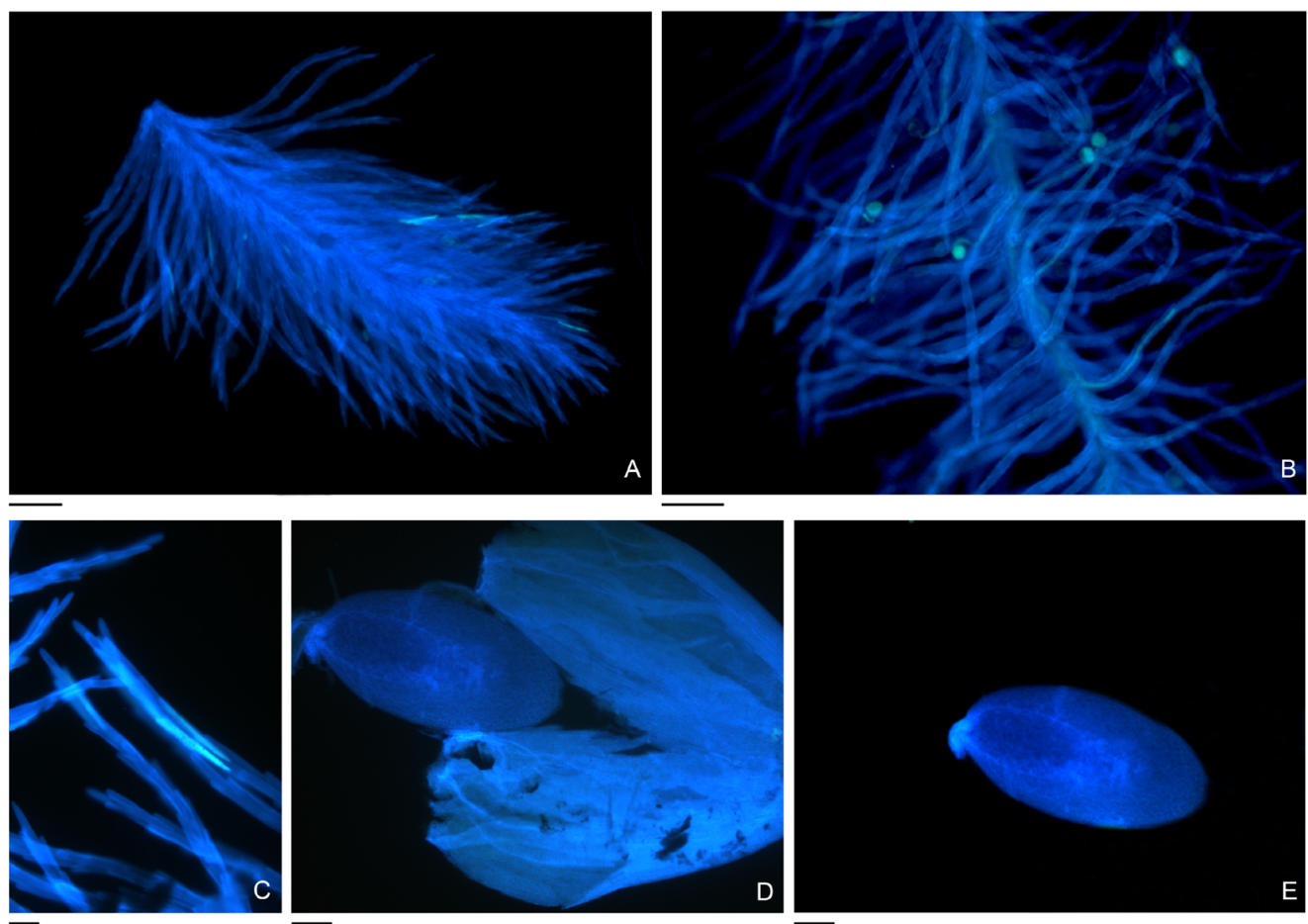

Fig. 6. Detalle del pistilo de P. lilloi. A. Estigma plumulado. B. Ramificaciones del estigma y algunos granos de polen adheridos al estigma. C. Papila estigmática. D. Óvulo maduro y ovario. E. Detalle del óvulo maduro, a $3 \mathrm{~h}$ posteriores a la antesis. Nótese el contorno de calosa que rodea al saco embrionario. Escalas= A-E: $25 \mu \mathrm{m}$.

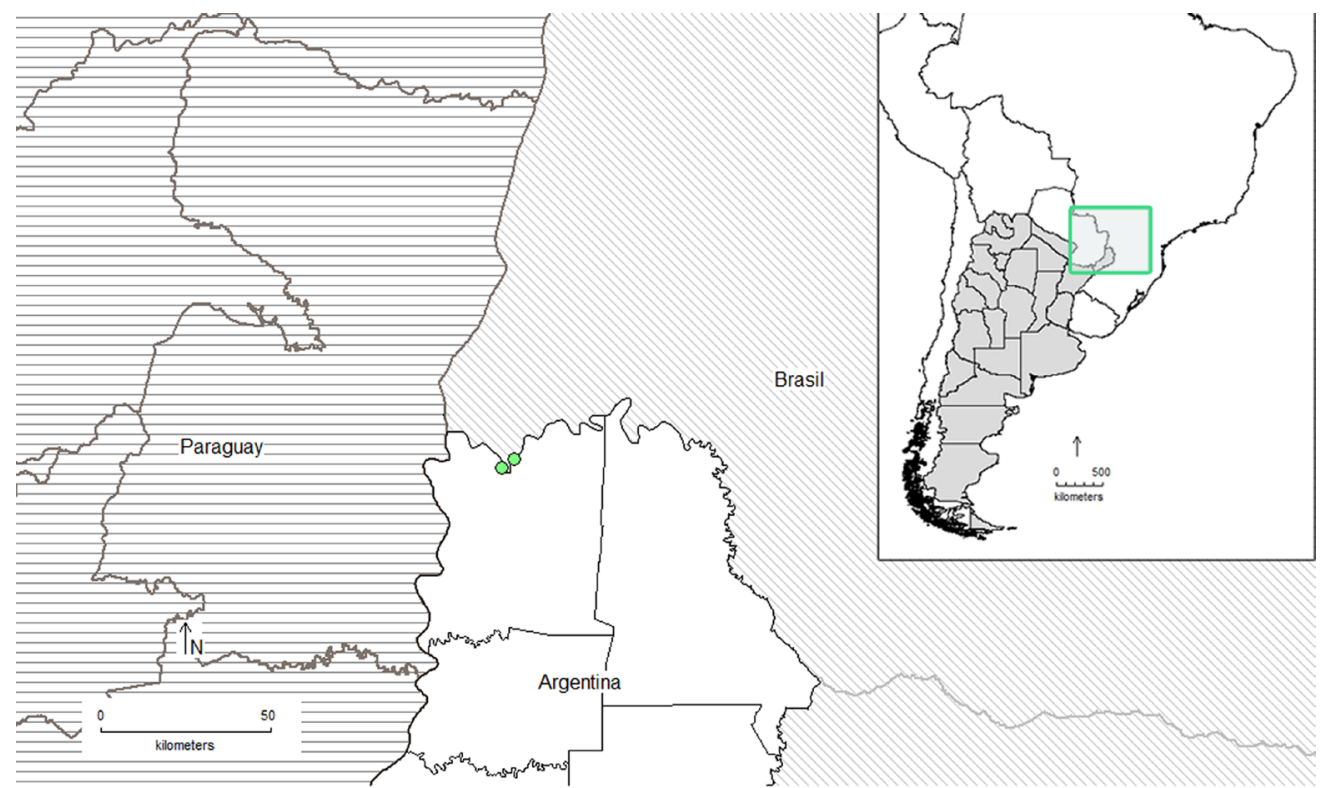

Fig. 7. Localización geográfica del área ocupada por el endemismo de P. lilloi. Nótese circunscripción restringida a las Cataratas del Iguazú (Argentina - Brasil). 


\section{Discusión}

Los sistemas genéticos en Paspalum tienen una asociación estrecha con el nivel de ploidía. Alrededor del 20\% de las especies del género fueron caracterizadas según su sistema genético, y los diploides son funcionalmente de reproducción sexual (Ortiz et al., 2013). Todos los citotipos diploides de Paspalum presentan un saco embrionario tipo Polygonum y $P$. lilloi no es una excepción a la regla. Además, carece de potencial para apomixis, puesto que no se observaron indicios de formación de sacos embrionarios adicionales al meiótico como ocurre en algunas especies (Ortiz et al., 2013).

La compatibilidad polen-pistilo refleja el grado de éxito esperado en cruzamientos conespecificos en las plantas sexuales. La polinización exitosa en producir una semilla requiere que el polen transite a través de diversos tejidos florales para fecundar la oósfera y la célula central (Swanson et al., 2004). Los cariopsis de $P$. lilloi presentaron una proporción 2:3 de contenido relativo de ADN en los tejidos del embrión y el endospermo, que indica que tienen un origen reproductivo sexual, en concordancia con la presencia exclusiva de sacos embrionarios meióticos.

Tanto la autofertilidad como la autoesterilidad han sido reportadas en los diploides de Paspalum, pero la mayoría son alógamos por autoincompatibilidad polen-pistilo (Ortiz et al., 2013). La autopolinización, autocompatibilidad y autofecundación como mecanismos de autogamia son infrecuentes en los citotipos diploides de Paspalum. Entre los pocos casos estudiados experimentalmente se mencionó a $P$. juergensii Hack. (Burson, 1991, 1992), P. pumilum Nees (Reutemann, 2020) y P. repens J. P. Berg. (Burson, 1997), todas especies exclusivamente diploides que están ampliamente distribuidas en América (Zuloaga \& Morrone, 2005; Reutemann, 2020). Por primera vez se describe autocompatibilidad, autofertilidad y autofecundación en $P$. lilloi, que también es una especie exclusivamente diploide, pero cuya distribución geográfica es restringida por el hábitat específico en el cual crece.

Durante la polinización, el grano de polen hace contacto con las células receptivas del estigma, que favorece al crecimiento del polen de algunos genotipos, mientras que se opone o rechaza otros (Swanson et al., 2004). Las gramíneas poseen una superficie estigmática seca (Connor, 1979) de modo que los granos de polen deben hidratarse para iniciar la adhesión al estigma. Esta interacción polenpistilo establece límites de autogamia (endogamia) o de alogamia (exogamia). Paspalum lilloi resultó completamente autofértil, con crecimiento del tubo polínico y alta producción de semillas en condiciones controladas de autopolinización.

La autopolinización y autofecundación son claramente dos etapas distintas dentro del proceso de autogamia. La inducción de autofecundación en plantas autoincompatibles mediante polen foráneo de un citotipo diferente e incluso de una especie emparentada, también llamada efecto mentor, en ocasiones origina progenies viables (Quarin \& Norrmann, 1987; Burton \& Hanna, 1992; Hörandl, 2010; Delgado et al., 2014). Este efecto ha sido reportado principalmente en cruzamientos heteroespecíficos, y no requiere de polen viable ni funcional (Nettancourt, 2001; Hojsgaard \& Hörandl, 2019), excepto que se pretenda hibridación inter- específica. Por otro lado, la polinización heteroespecífica en plantas autocompatibles y autógamas como $P$. lilloi puede afectar de diversa manera la producción de semillas. En este caso, la presencia de polen heteroespecífico en el estigma de $P$. lilloi tuvo consecuencias negativas en la autofecundación, ya que la producción de semillas fue menor en los experimentos de polinización heteroespecífica en comparación con los casos en los que la polinización fue exclusivamente conespecifica. Este efecto probablemente se deba a que existieron interferencias del polen extraño sobre el potencial de autogamia esperado. En general, se espera que las fallas en la polinización resulten menos intensas en especies autocompatibles o autógamas (Larson \& Barret, 2000). Asumiendo que no existen factores extrínsecos a la polinización y que la provisión de polen compatible a los estigmas receptivos fue suficiente en calidad y cantidad, las fallas en la producción de semillas que ocasionaron una disminución de la proporción de espiguillas fructificadas, podrían relacionarse con una inhibición física por obstrucción y/o química causada por la presencia simultánea de polen propio y foráneo, sin embargo, no encontramos evidencias claras a favor de uno $\mathrm{u}$ otro factor. McLernon et al. (1996) observaron que la disminución en la producción de semillas en especies autógamas en presencia de polen heteroespecífico podría 


\section{A. V. Reutemann et al. - Sistema genético de Paspalum lilloi}

explicarse como consecuencia de la interferencia física (por obstrucción) o química que afectan a la deposición, adherencia y germinación del polen propio en los estigmas. Otra posible explicación del bajo número de semillas puede ser el aborto temprano de la semilla autofecundada debido a la depresión por endogamia (Tas \& Van Dijk, 1999); sin embargo, no hemos encontrado espiguillas con desarrollo parcial de cariopsis $u$ otros indicios en ninguno de los experimentos. Alternativamente, es posible que haya ocurrido cierta interacción inhibitoria de la fecundación por competencia del polen propio y el heteroespecífico, puesto que cabría esperar que actúen barreras de preapareamiento entre $P$. bertonii y $P$. lilloi en los pistilos de esta última. Los mecanismos de aislamiento reproductivo podrían estar actuando entre ambas especies.

\section{Estado de conservación y área del endemismo}

Paspalum lilloi posee distribución geográfica acotada, restringida a la zona correspondiente a las Cataratas del Iguazú (Argentina - Brasil) sobre el Rio homónimo. Esta especie es endémica y cuenta con una baja capacidad de dispersión, debido principalmente a su especialización ecológica reófila, con condiciones ambientales altamente específicas, de suelos rocosos húmedos a anegados, con aguas corrientes torrentosas permanentes y altos niveles de humedad relativa ambiente, incluso neblina permanente en algunos sitios. Paspalum lilloi habita cuerpos de agua, formando sectores de pastizales higrófilos más o menos monoespecíficos en sectores del borde superior de las cascadas y saltos de las Cataratas del Iguazú, incluso habita en los paredones de la Garganta del Diablo, donde el torrente de agua posee su mayor volumen y fuerza de arrastre. Se trata de una especie reófila rupícola firmemente arraigada a las piedras y resistente a la fuerza de arrastre de la corriente hídrica.

El área estimada de ocupación actual de este endemismo apenas excede aguas arriba y aguas abajo de las Cataratas de Iguazú (Argentina Brasil). Resta explorar con mayor exhaustividad la presencia remanente de $P$. lilloi en sitios similares circundantes en Paraguay, tales como en la flora higrófila asociada a los Saltos del Monday (sobre el Río Monday) y en los rápidos del Río Acaray, aunque no existen colecciones recientes de la especie en dicho país (Zuloaga et al., 2014).
El estado de conservación actual de P. lilloi es en peligro crítico (CR) dado que se encuentra circunscripto a un área menor de $100 \mathrm{~km}^{2} \mathrm{y}$ todos los sitios de localización se encuentran limitados a las áreas protegidas que rodean a las Cataratas del Iguazú en Argentina y Brasil. La conservación del hábitat especializado de $P$. lilloi resulta clave para evitar su extinción y para ello es necesario aunar esfuerzos entre los tres países (Argentina, Brasil y Paraguay) para conservar esta especie amenazada luego del impacto antrópico ocurrido sobre sus poblaciones naturales. Felizmente, las Cataratas del Iguazú están dentro de un área protegida y, dada su importancia como atracción turística internacional, parece poco probable que esa área sea alterada sustancialmente por otras actividades humanas. Sin embargo, las fluctuaciones del nivel del agua en el caudal del rio Iguazú, podrían comprometer la conservación a largo plazo. Resulta prioritario aumentar los esfuerzos para determinar el tamaño de las poblaciones existentes como el grado de variabilidad genética que presentan y simultáneamente conservar germoplasma para restauración. Los datos obtenidos permitirán concretar el registro de $P$. lilloi en la lista roja de especies amenazadas de UICN y proponer la generación de instrumentos legales que garanticen su protección.

\section{ConClusión}

Paspalum lilloi es una especie diploide, sexual, autocompatible y autofértil, cuya distribución geográfica se encuentra restringida a las Cataratas del Iguazú y en peligro crítico de conservación. Las plantas en peligro crítico de extinción como las endémicas adaptadas a hábitats altamente especializados tienen alto riesgo de fallas en la polinización cuando existen altos niveles de fragmentación de sus poblaciones, y la existencia de autogamia asegura la fertilidad a pesar de la inherente depresión por consanguinidad esperada.

\section{Agradecimientos}

Los autores agradecemos el apoyo y las facilidades otorgadas por la Administración de Parques Nacionales, autoridades regionales y 
del P. N. Iguazú y a sus guardaparques por las atenciones recibidas. AVR y AIH agradecen las facilidades otorgadas para consultar especímenes a los curadores de los siguientes herbarios: CTES, BAA, SI, CORD en Argentina y PY, FACEN, FCQ, y SCP de Paraguay. Agradecemos la asistencia técnica de la Lic. F. Eckers en CF. Este trabajo fue financiado por la Universidad Nacional de Misiones (SGCyT - UNaM, PI-16Q1082), Universidad Nacional del Nordeste (SGCyT-UNNE PI 11A003 y PI 16A002), Agencia Nacional de Promoción Científica y Tecnológica (ANPCyT-PICT 2017 4203 y PICT 2012-0261), ANPCyT-UNNE (PICTO 2011-080). AVR es becaria posdoctoral y los demás autores son investigadores del Consejo Nacional de Investigaciones Científicas y Técnicas (CONICET).

\section{Contribución de los autores}

AIH, JRD y AVR diseñaron la investigación. GHR, EJM, MS y AIH realizaron las colectas. AVR obtención, análisis e interpretación de datos y redactó la primera versión del manuscrito. Todos los autores revisaron y acordaron la versión final. AIH editó la versión final.

\section{Bibliografía}

ALISCIONI, S. S. 2000. Anatomía ecológica de algunas especies del género Paspalum (Poaceae, Panicoideae, Paniceae). Darwiniana 38: 187-207.

ALISCIONI, S. S. 2002. Contribución a la filogenia del género Paspalum (Poaceae: Panicoideae: Paniceae). Ann. Missouri Bot. Gard. 89: 504-523. https://doi.org/10.2307/3298593

ANTON, A. \& A. E. COCUCCI. 1984. The grass megagametophyte and its possible phylogenetic implications. Pl. Syst. \& Evol. 146: 117-121. https://doi.org/10.1007/BF00984058

BURSON, B. L. 1986. Pollen germination, pollen tube growth and fertilization following self and interspecific pollination of Paspalum species. Euphytica 36: 641-650. https://doi.org/10.1007/BF00041514

BURSON, B. L. 1991. Genome relationships between tetraploid and hexaploid biotypes of Dallisgrass, Paspalum dilatatum. Bot. Gaz. 152: 219-223. https://doi.org/10.1086/337883
BURSON, B. L. 1992. Cytogenetic relationships between Paspalum dilatatum y $P$. cromyorrhizon, P. indecorum y P. laxum. Int. J. Plant Sci. 153: 244249. https://doi.org/10.1086/297028

BURSON, B. L. 1997. Apomixis and sexuality in some Paspalum species. Crop Sci. 37: 1347-1351. https://doi. org/10.2135/cropsci1997.0011183X003700040052x

BURTON, G. W. \& W. W. HANNA. 1992. Using apomictic tetraploids to make a self-incompatible diploid Pensacola bahiagrass clone set seed. $J$. Hered. 83: 305-306. https://doi.org/10.1093/oxfordjournals.jhered.a111217

CHASE, A. 1929. The North American species of Paspalum. Contr. U.S. Natl. Herb. 28: I-XVII: 1-310.

CLARKE J. L. 1851. Researches into the Structure of the Spinal Chord. Phil. Trans. Roy. Soc. London, 141: 607-621. https://doi.org/10.1098/rstl.1851.0029

CONNOR, H. E. 1979. Breeding systems in the grasses: a survey. New Zealand J. of Bot. 17: 547-574. https://doi.org/10.1080/0028825X.1979.10432571

de NETTANCOURT, D. 2001. Incompatibility and incongruity in wild and cultivated plants, 2nd Edn. Berlin: Springer. https://doi.org/10.1007/978-3-662-04502-2

DAWKINS, M. D. \& J. N. OWENS. 1993. In vitro and In vivo Pollen Hydration, Germination, and Pollen-Tube Growth in White Spruce, Picea glauca (Moench) Voss. Int. J Plant Sci. 154: 506-521. https://doi.org/10.1086/297134

DELGADO, L., F. GALDEANO, M. E. SARTOR, C. L. QUARIN, F. ESPINOZA \& J. P. A ORTIZ. 2014. Analysis of variation for apomictic reproduction in diploid Paspalum rufum. Ann. Bot. 113: 1211-1218. https://doi.org/10.1093/aob/mcu056

DENHAM, S. S. 2005. Revisión sistemática del subgénero Harpostachys de Paspalum (Poaceae: Panicoideae: Paniceae). Ann. Missouri Bot. Gard. 92: 463-532.

https://doi.org/10.1007/s00606-010-0327-9

ESPINOZA, F. \& C. L. QUARIN. 1997. Cytoembryology of $P$. chaseanum and sexual diploid biotypes of two apomictic Paspalum species. Aust. J. Bot. 45: 871877. https://doi.org/10.1071/BT96055

ESPINOZA, F., M. H. URBANI, E. J. MARTINEZ \& C. L. QUARIN. 2001. The breeding systems of three Paspalum species with forage potential. Trop. Grassl. 35: 211-217.

GALDEANO, F., M. H. URBANI, M. E. SARTOR, A. I. HONFI, F. ESPINOZA \& C. L. QUARIN. 2016. 


\section{A. V. Reutemann et al. - Sistema genético de Paspalum lilloi}

Relative DNA content in diploid, polyploid, and multiploid species of Paspalum (Poaceae) with relation to reproductive mode and taxonomy. $J$. Plant Res. 129: 697-710.

https://doi.org/10.1007/s10265-016-0813-4

HIJMANS, R. J., L. GUARINO, C. BUSSINK, P. MATHUR, M. CRUZ, I. BARRENTES \& E. ROJAS. 2004. DIVA-GIS. V 5.0. A geographic information system for the analysis of species distribution data.

HIJMANS, R. J. \& J. ELITH. 2017. Species distribution modeling with R. $R$ CRAN Project.

HOJSGAARD, D. H., A. I. HONFI, G. H. RUA \& J. R. DAVIÑA. 2009. Chromosome numbers and ploidy levels of Paspalum species from subtropical South America (Poaceae). Genet. Resour. Crop. Evol. 56: 533-545. https://doi.org/10.1007/s10722-008-9384-0

HOJSGAARD, D. H. \& E. HÖRANDL. 2019. The Rise of Apomixis in Natural Plant Populations. Front. Plant Sci. 10: 358. https://doi.org/10.3389/fpls.2019.00358

HOJSGAARD, D. \& M. SCHARTL. 2021. Skipping sex: A nonrecombinant genomic assemblage of complementary reproductive modules. Bioessays 43: e2000111. https://doi.org/10.1002/bies.202000111

HONFI, A. I., C. L. QUARIN \& J. F. M VALLS. 1990. Estudios cariológicos en gramíneas sudamericanas. Darwiniana 30: 87-94.

HONFI, A. I. 2003. Citoembriología de poliploides impares en el género Paspalum L. (Panicoideae: Gramineae). Tesis Doctoral, Universidad Nacional de Córdoba, Argentina.

HONFI, A. I., O. MORRONE \& F. O. ZULOAGA. 2021. Chromosome numbers and ploidy levels of some Paniceae and Paspaleae species (Poaceae, Panicoideae). Ann. Missouri Bot. Gard. 106: 234244. https://doi.org/10.3417/2021585

HÖRANDL, E. 2010. The evolution of self-fertility in apomictic plants. Sex. Plant Reprod. 23: 73-86. https://doi.org/10.1007/s00497-009-0122-3

KHO, Y. O. \& J. BAER. 1968. Observing pollen tubes by means of fluorescence. Euphytica 17: 298-302. https://doi.org/10.1007/BF00021224

LARSON B. M. H. \& S. C. H. BARRETT. 2000. A comparative analysis of pollen limitation in flowering plants. Biol. J. Linn. Soc. 69: 503-520. https://doi.org/10.1006/bijl.1999.0372

MARTINEZ E. J. \& C. L. QUARIN. 1999. Citoembriología y comportamiento reproductivo de un citotipo diploide de Paspalum hydrophilum y sus híbridos con P. palustre (Poaceae, Paniceae). Darwiniana 37: 243-251

MORRONE, O., L. AAGESEN, M. A. SCATAGLINI, D. L. SALARIATO, S. S. DENHAM, M. A. CHEMISQUY \& F. O. ZULOAGA. 2012. Phylogeny of the Paniceae (Poaceae: Panicoideae): integrating plastid DNA sequences and morphology into a new classification. Cladistics 28: 333-356. https://doi.org/10.1111/j.1096-0031.2011.00384.x

McLERNON, S. M., S. D. MURPHY \& L. W. AARSSEN. 1996. Heterospecific pollen transfer between sympatric species in a mid-successional old-field community. Am. J. Bot. 83: 1168-1174. https://doi.org/10.1002/j.1537-2197.1996.tb13897.x

NICORA, E. G. \& Z. E. RÚGOLO DE AGRASAR. 1987. Los géneros de gramíneas de América austral. Buenos Aires: Editorial Hemisferio Sur.

NOGLER G. A. 1984. Gametophytic apomixis. In: JOHRI, B. M. (Ed.) Embryology of angiosperms. Springer, Berlin, Heidelberg. https://doi.org/10.1007/978-3-642-69302-1_10

ORTIZ J. P. A., C. L. QUARIN, S. C. PESSINO, C. ACUÑA, E. J. MARTÍNEZ, F. ESPINOZA, D. H. HOJSGAARD, M. E. SARTOR, M. E. CÁCERES \& F. PUPILLI. 2013. Harnessing apomictic reproduction in grasses: what we have learned from Paspalum. Ann. Bot. 112: 767-787. https://doi.org/10.1093/aob/mct152

PARODI, L. R. \& E. G. NICORA. 1966, inéd. Apuntes para una monografía del género. No publicado, copia en PEFyGV-UNaM.

QUARIN, C. L. \& G. A. NORRMANN. 1987. Cytology and reproductive behavior of Paspalum equitans, $P$. ionanthum, and their hybrids with diploid and tetraploid cytotypes of P. cromyorrhizon. Bot. Gaz. 148: 386-391. https://doi.org/10.1086/337667

QUARIN C. L. \& B. L. BURSON. 1991. Cytology of Sexual and apomictic Paspalum species. Cytologia 56: 223228. https://doi.org/10.1508/cytologia.56.223

QUARIN, C. L. 1992. The nature of apomixis and its origin in Panicoid grasses. Apomixis Newsl. 5: 8-15.

REUTEMANN, A. V., E. J. MARTÍNEZ, M. SCHEDLER, G. H. RUA, J. R. DAVIÑA \& A. I. HONFI. 2017. Paspalum lilloi Hack. (Poaceae). In: Marhold, K. (ed.), IAPT/IOPB chromosome data 26. Taxon 66: 32-33. https://doi.org/10.12705/666.30

REUTEMANN, A. V. 2020. Diversidad genética en especies del género Paspalum (Poaceae) con diferentes sistemas genéticos. Tesis Doctoral, Universidad Nacional de Córdoba. 
RUA, G. H., P. R. SPERANZA, M. VAIO \& M. ARAKAKI. 2010. A phylogenetic analysis of the genus Paspalum (Poaceae) based on cpDNA and morphology. Plant Syst. Evol. 288: 227-243. https://doi.org/10.1007/s00606-010-0327-9

SCATAGLINI, M. A., F. O. ZULOAGA, L. M. GIUSSANI, S. S. DENHAM \& O. MORRONE. 2014. Phylogeny of New World Paspalum (Poaceae, Panicoideae, Paspaleae) based on plastid and nuclear markers. Plant Syst. Evol. 300: 1051-1070. https://doi.org/10.1007/s00606-013-0944-1

SWANSON, R., A. F. EDLUND \& D. PREUSS. 2004. Species specificity in pollen-pistil interactions. Annu. Rev. Genet. 38: 793-818. https://doi.org/10.1146/annurev.genet.38.072902.092356

TAS, I. C. Q. \& P. J. VAN DIJK. 1999. Crosses between sexual and apomictic dandelions (Taraxacum). I. The inheritance of apomixis. Heredity 83: 707-714. https://doi.org/10.1046/j.1365-2540.1999.00619.x

TÜRPE, A. 1967. Histotaxanomía de las especies argentinas del género Paspalum. Lilloa 32: 1-272.

UICN v.14. 2019. Comité de Estándares y Peticiones de la UICN. 2019. Directrices de uso de las Categorías y Criterios de la Lista Roja de la UICN. Versión 14. Disponible en https://www.iucnredlist.org/es/ resources/redlistguidelines

URBANI, M. H. 1996. Estudios sobre citología, sistema reproductivo y compatibilidad polen-pistilo en
Panicum dichotomiflorum y Paspalum fasciculatum (Gramineae, Paniceae). Darwiniana 34: 193-198.

VALLS, J. F. M. 1987. Recursos genéticos de especies de Paspalum no Brasil. Encuentro Internacional sobre mejoramiento genético de Paspalum 3-13, Nova Odessa, Brasil.

YOUNG, B. A., R. T. SHERWOOD \& E. C. BASHAW. 1979. Cleared-pistil and thick-sectioning techniques for detecting aposporous apomixis in grasses. Canad. J. Bot. 57: 1668-1672. https://doi.org/10.1139/b79-204

ZILLI, A. L., E. A. BRUGNOLI, F. MARCÓN, M. B. BILLA, E. F. RIOS, E. J. MARTÍNEZ \& C. A ACUÑA. 2015. Heterosis and expressivity of apospory in tetraploid bahiagrass hybrids. Crop Sci. 55: 11891201. https://doi.org/10.2135/cropsci2014.10.0685

ZULOAGA, O. F., O. MORRONE, G. DAVIDSE, T. S. FILGUEIRAS, P. M PETERSON, R. J. SORENG \& E. JUDZIEWICZ. 2003. Catalogue of New World Grasses (Poaceae): III Subfamilies Panicoideae, Aristidoideae, Arundinoideae and Danthonioideae. Contrib. U. S. Nat. Herb. Smithsonian Inst. 46: 1-662.

ZULOAGA, F. O. \& O. MORRONE. 2005. Revisión de las Especies de Paspalum para América del Sur Austral. Monogr. Syst. Bot. Mo. Bot. Gard. 102: 1-297.

ZULOAGA, O. F., O. MORRONE \& J. F. PENSIERO. 2014. Gramineae VI. Paniceae II. Conservatoire et Jardin botaniques de la Ville de Genève (Ed.) Flora del Paraguay 45: 1-399. 